\title{
THE EFFECTS OF STIMULATION OF THE CAROTID SINUS BARORECEPTORS UPON THE ACTIVITY OF THE LONG CILIARY NERVE
}

\author{
Hiromasa OKada, Nagao Kado and Isamu Nisida* \\ Department of Physiology, Tottori University School of Medicine, Yonago
}

HERING ${ }^{10)}$ claimed that, in the rabbit, sino-aortic denervation produced a mydriasis, exophthalmos and widening of palpebral fissure. $\mathrm{KoCH}^{12-13}$ also observed that, in the dog, a rise of the pressure in the carotid sinus evoked a miosis, enophthalmos and narrowing of palpebral fissure, and that the miosis could still be produced after cutting the cervical sympathetic nerves. He concluded that the baroreceptor stimulation caused a diminution of the sympathetic tonus and an increase of the parasympathetic tonus.

On the other hand, regarding the action potential study of the sympathetic nerve in the carotid sinus reflex, BRONK et al..$^{2-4)}$ have demonstrated that stimulation of the baroreceptors, by raising the pressure of the isolated carotid sinus or by intravenous injection of adrenalin, reduces reflexly the impulse activity in the cardiac and cervical sympathetic nerves. Several authors have made some similar observations in the efferent impulses in the cardiac sympathetic nerve ${ }^{8)}$, cervical sympathetic nerve $\mathrm{e}^{1,11)}$, splanchnic nerve ${ }^{1,5,9)}$, and renal branch of the abdominal sympathetic nerve ${ }^{6)}$. We ${ }^{15)}$ have recently showed that the efferent impulses in the long ciliary nerve of the cat, in which the cilio-spinal centers are completely deafferenated, are abolished by intravenous injection of adrenalin without mediation of the carotid sinus nerves. However, the reflex response in the ocular sympathetic nerves to stimulation of the baroreceptors has not been investigated.

The present study has therefore been made to clarify the response of the efferent impulses in the ocular sympathetic nerves to raising the pressure in the carotid sinus of the cat and dog, isolated from the general circulation.

\section{METHODS}

The experiments were made on cats $(2.0 \sim 4.0 \mathrm{~kg})$ anesthetized with urethane $(0.25 \mathrm{~g} / \mathrm{kg})$ and on dogs $(6 \sim 10 \mathrm{~kg})$ anesthetized with morphine hydrochloride $(5 \mathrm{mg} / \mathrm{kg})$ and urethane $(1 \mathrm{~g} / \mathrm{kg})$. In some cases the animals were decerebrated by means of the mid-collicular transection under such anesthesia.

The unilateral carotid sinus was isolated from the general circulation by ligating

Received for publication April 27, 1961

* 阙田博匡, 門 長生, 西田 勇 
all branches of the common carotid artery and finally tying off the common carotid itself ${ }^{14)}$. A small polythene tube was then introduced into the common carotid artery and connected to a bottle containing the defibrinated pig or cattle blood of $38^{\circ} \mathrm{C}$. On the other hand, the outflow tube was inserted into the external carotid artery. Thus the carotid sinus was continually perfused under the constant pressure of $120 \mathrm{~cm} \mathrm{H} \mathrm{H}_{2} \mathrm{O}$. Raising the pressure in the carotid sinus was performed by pressing a syringe which was connected to the inflow tube. In some cases the carotid sinus nerve was prepared using an approach similar to that described by vON EULER et al. ${ }^{7}$, and stimulated with an electronic stimulator of Nihon Koden MSE-2 type.

The unilateral long ciliary nerve was exposed and divided into small nerve strands by means of the method mentioned in previous reports ${ }^{15-16}$. The action potentials from the nerve were led with a unipolar platinum electrode and recorded with a magnetic oscillograph connected to an R-C coupled amplifier under visual control of a cathoderay oscillograph. As an indifferent electrode, a silver plate was applied to the skin of the head. Systemic blood pressure was recorded from a femoral artery by means of a mercury manometer.

\section{RESULTS AND DISCUSSIONS}

\section{Effects of electrical stimulation of the sinus nerves.}

As preliminary experiments, the reflex effects of the electrical stimulation of the central end of the severed sinus nerve upon the efferent impulses in the long ciliary nerve were examined. The reflex response in the long ciliary nerve of non-decerebrate cats was various; in some cases a diminution or abolition of the efferent impulses in the long ciliary nerve (an inhibitory effect) was obtained, and in other cases reversely an increase of the impulse discharge (a facilitatory effect) was recognized as illustrated in FIG. $1 \mathrm{~A}$ and B. However, in general there was a tendency that with the stimulation of low voltage $(3 \sim 5$ volts $)$ the inhibitory effect was frequently elicited, whereas with the one of moderate strength ( $8 \sim 10$ volts) the facilitatory effect. Such reflex effects could be produced not only with the stimulation of the ipsilateral sinus nerve, but also of the contralateral nerve. In decerebrate cats similar observations were recognized. Such a complication in the response to the electrical stimulation of the sinus nerve might be due to the simultaneous stimulation of the dual fibers arising from the baroreceptors and chemoreceptors. Therefore, in order to stimulate only the baroreceptors in the carotid sinus, the perfusion experiments were attempted.

\section{Effects of raising the carotid sinus pressure.}

The experiment on cats: In cats anesthetized with urethane the unilateral carotid sinus was isolated from the circulation and perfused with defibrinated blood. When the intrasinusal pressure was increased by pressing a syringe connected to the perfusion apparatus, a gradual fall in systemic blood pressure was produced as observed frequently by many authors, whereas the electrical activity 


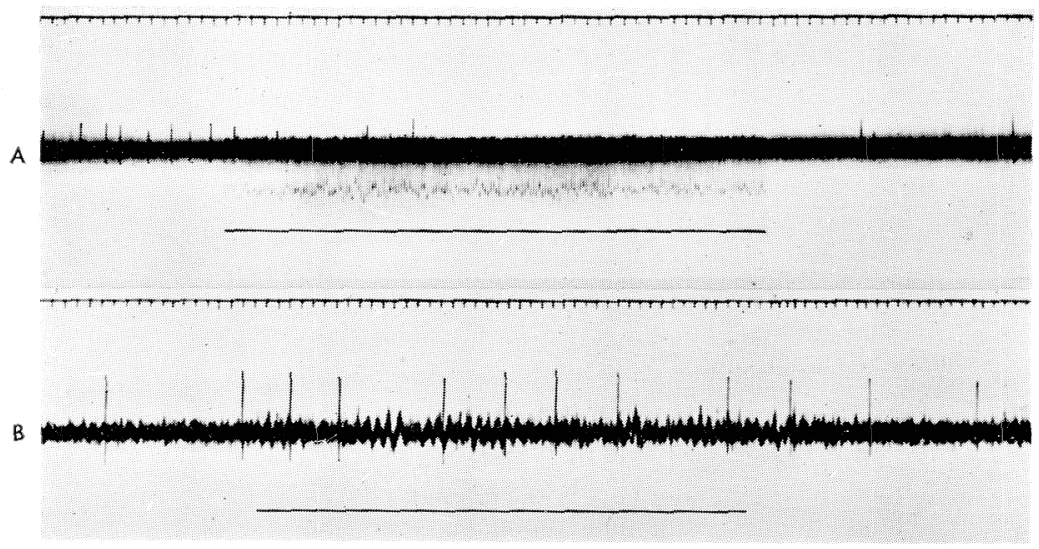

FIG. 1. Responses of the long ciliary nerve to repetitive stimulation of the sinus nerve.

A : inhibitory effect. Non-decerebrate cat, $3.1 \mathrm{~kg}$. Action potentials : led from a few active units of the left long ciliary nerve. The left sinus nerve was centrally stimulated with the pulses whose duration, intensity and frequency were $1 \mathrm{msec}, 5$ volts and $50 \mathrm{c} / \mathrm{sec}$. respectively. The period of stimulation was indicated by a bar. Downward spikes: stimulation artifact. Time scale, $1 / 12 \mathrm{sec}$.

B : facilitatory effect. Non-decerebrate cat, $2.8 \mathrm{~kg}$. Action potentials: led from a single active unit of the left long ciliary nerve. The right sinus nerve was centrally stimulated with the pulses whose duration, intensity and frequency were $1 \mathrm{msec}, 9$ volts and $50 \mathrm{c} / \mathrm{sec}$. respectively.

of the long ciliary nerve was decreased abruptly and its decreased activity was maintained during the rise of the carotid sinus pressure. When the carotid sinus pressure was decreased to its original level, the systemic blood pressure was gradually increased to that prior to stimulation, whereas the decreased impulse discharge from the long ciliary nerve was instantaneously returned to the original activity. The typical examples are shown in FIG. $2 \mathrm{~A}$ and B.

The decreased activity in the long ciliary nerve following the increase of the carotid sinus pressure became usually greater as the grade of the rise of its pressure was enhanced. However, no increased activity of the long ciliary nerve to stimulation of baroreceptors was recognized. These changes in the long ciliary nerve and in systemic blood pressure on raising the carotid sinus pressure were abolished by cutting the ipsilateral sinus nerve. In the aforementioned experiments, in order to prevent the damage of the impulse transmission in the superior cervical ganglion brought about by anemia, stimulation of the baroreceptors was made in the carotid sinus contralateral to the long ciliary nerve of the experimental side.

In decerebrate cats with transection of the brainstem at the mid-collicular level, a similar inhibitory effect of the long ciliary nerve, by stimulating the 


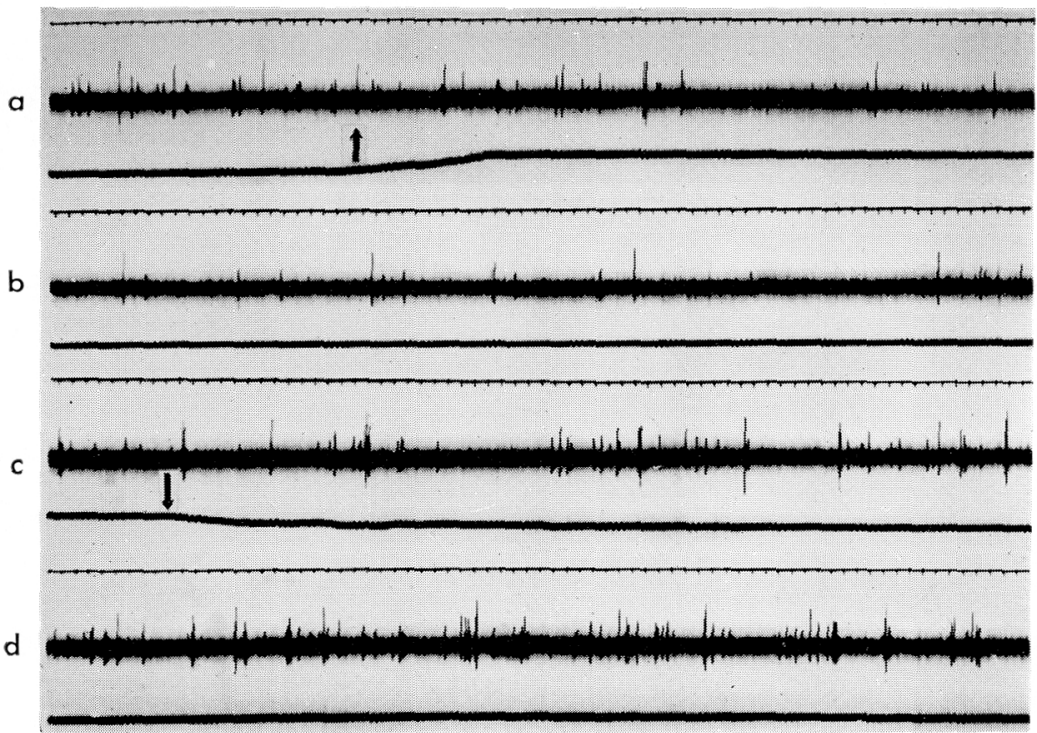

FIG. 2A. Effects of raising the carotid sinus pressure upon the activity of the long ciliary nerve in the non-decerebrate cat.

Non-decerebrate cat, $2.6 \mathrm{~kg}$. Action potentials: led from a few active units of the left long ciliary nerve. The right carotid sinus was perfused with defibrinated blood. $a, b, c$ and $d$ were a series of record. Tracings from above downwards: time in $1 / 12 \mathrm{sec}$, action potentials, signal. The carotid sinus pressure was increased from $0 \mathrm{mmHg}$ to $200 \mathrm{mmHg}$ at upward signal in record $a$ and decreased to the original level at downward signal in record $c$.

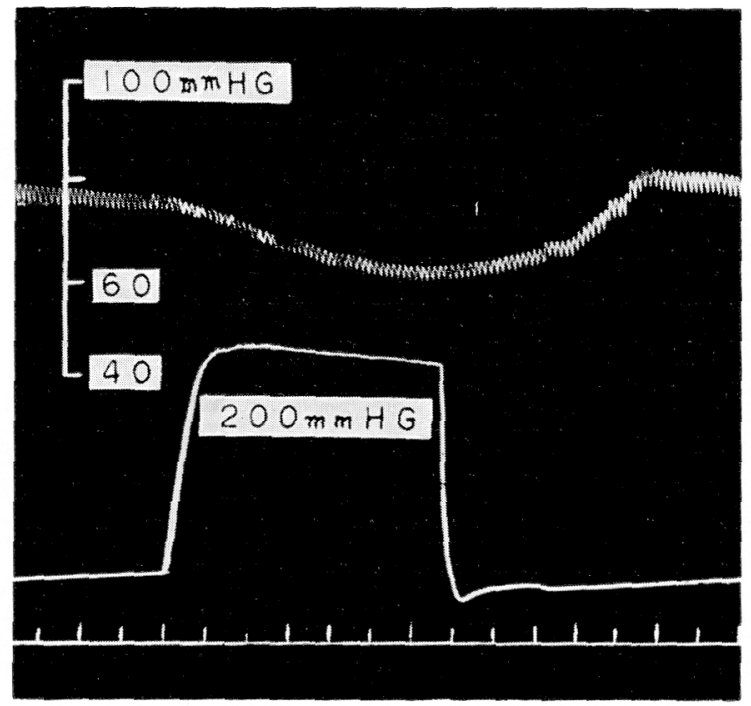

FIG. 2B. Effects of raising the carotid sinus pressure upon systemic blood pressure.

This curve was recorded at the same time with electrogram in A. Records from above downwards: systemic blood pressure, carotid sinus pressure, time in $3 \mathrm{sec}$. 


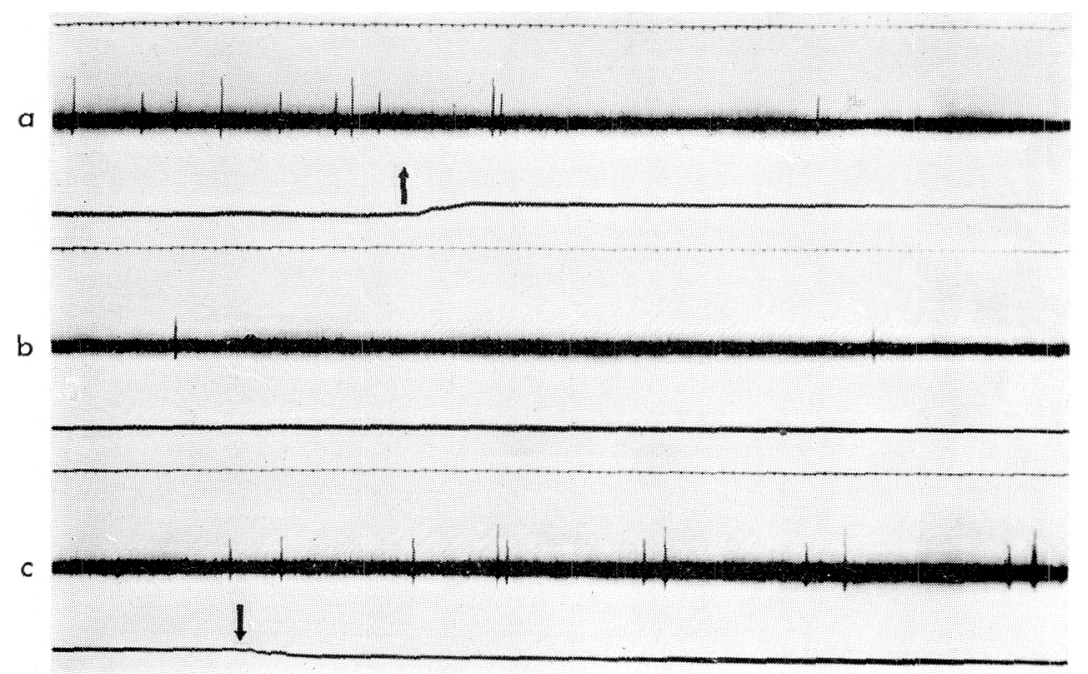

FIG. 3. Effects of raising the carotid sinus pressure upon the activity of the long ciliary nerve in the decerebrate cat.

Decerebrate cat, $3.4 \mathrm{~kg}$. Action potentials: led from a few active units of the left long ciliary nerve. The right carotid sinus was perfused with defibrinated blood. Tracings from above downwards: time in 1/12 sec, action potentials, signal. The carotid sinus pressure was increased from $0 \mathrm{mmHg}$ to $180 \mathrm{mmHg}$ at upward signal in record $a$ and decreased to the original level at downward signal in record $c$.

carotid sinus baroreceptors, was also observed as shown in Fig. 3.

The experiment on dogs: In the dog it was found that stimulation of the baroreceptors, by increasing the pressure in the carotid sinus, caused bradycardia, a fall in systemic blood pressure and a decreased activity of the long ciliary nerve. "When the carotid sinus pressure was lowered to the original level, such a decreased activity was returned instantaneousiy to the activity prior to stimulation. An example is shown in FIG. 4. Severance of the sinus nerve abolished such reflex effects. Eliminating the reflex biadycardia by atropinization (0.2 $0.3 \mathrm{mg} / \mathrm{kg}$ ) had no appreciable effect on the decreased activity of the long ciliary nerve in response to stimulation of the carotid sinus. It may be stated, accordingly, that the decreased activity in the long ciliary nerve, resulting from raising the carotid sinus pressure, is not due to reflex bradycardia.

From the present study, it is concluded that in cats and dogs the afferent impulses from the carotid sinus baroreceptors act inhibitorily upon the impulse discharge from the ocular sympathetic centers in the medulla oblongata or spinal cord, but does not act facilitatorily. Accordingly, the facilitatory effect in the long ciliary nerve by electrical stimulation of the sinus nerve seems to be produced by stimulation of the chemoreceptor fibers. 
a

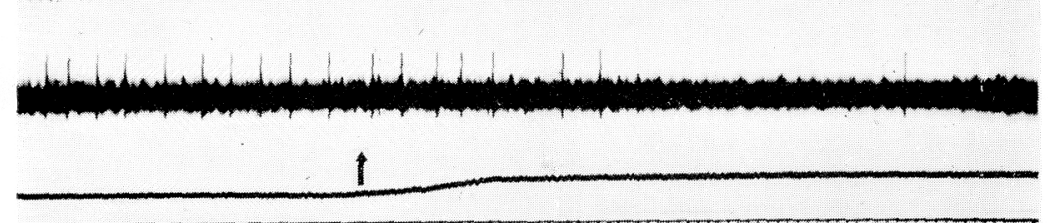

b

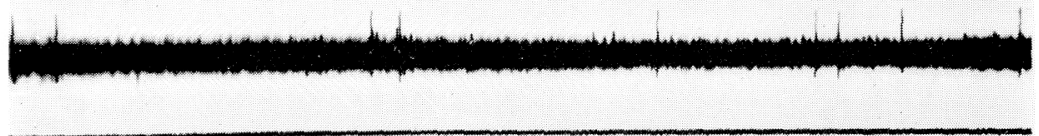

c

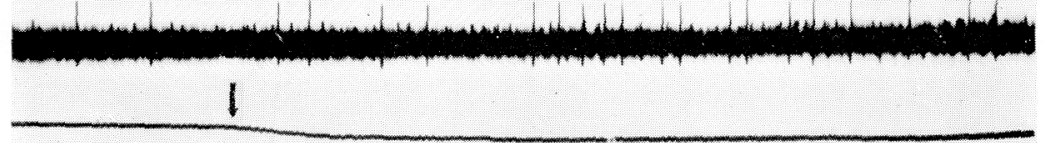

FIG. 4A. Effects of raising the carotid sinus pressure upon the activity of the long ciliary nerve in the dog.

Non-decerebrate dog, $10 \mathrm{~kg}$. Action potentials: led from a few active units of the left long ciliary nerve. The right carotid sinus was perfused with defibrinated blood. Tracings from above downwards: time in $1 / 12 \mathrm{sec}$, action potentials, signal. The carotid sinus pressure was increased from $0 \mathrm{mmHg}$ to $220 \mathrm{mmHg}$ at upward signal in record $a$ and decreased to the original level at downward signal in record $c$.

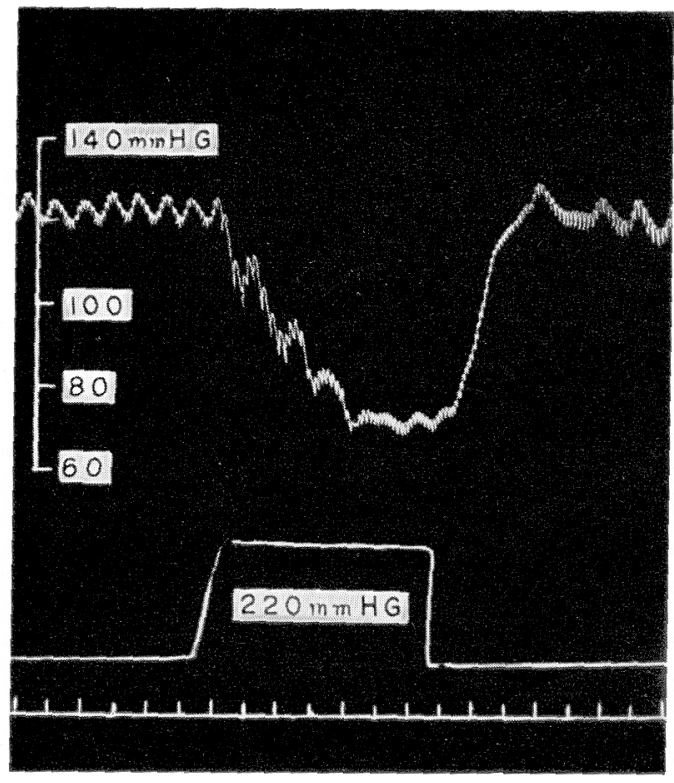

FIG. 4B. Effects of raising the carotid sinus pressure upon the systemic blood pressure. This curve was recorded simultaneously with electrogram in A. Records from above downwards: systemic blood pressure, carotid sinus pressure, time in 3 sec. 


\section{SUMMARY}

1. In anesthetized or decerebrate cats and dogs the effect of stimulation of the carotid sinus upon the activity of the long ciliary nerve was investigated by means of action potential study.

2. Electrical stimulation of the central end of the severed sinus nerve caused dual effects, inhibitory and facilitatory, in the impulse activity of the long ciliary nerve. However, raising the pressure in the carotid sinus, isolated and perfused, evoked only diminution or abolition of the ocular sympathetic activity, and such an inhibitory effect was abolished by cutting the sinus nerve.

3. From these results, it is concluded that the afferent impulses from the carotid sinus baroreceptors reflexly inhibit the impulse discharge from the ocular sympathetic centers.

\section{REFERENCES}

1) Adrian, E. D., Bronk, D. W. \& Phillips, G. Discharges in mammalian sympathetic nerves. J. Physiol. 74: 115, 1932.

2) BRonk, D. W. The nervous mechanism of cardiovascular control. Harvey Lect. 29: 245, 1933-4.

3) Bronk, D. W., Ferguson, L. K. \& Solandt, D. Y. Inhibition of cardiac accelerator impulses by the carotid sinus. Proc. Soc. Exp. Biol. \& Med. 31: 579, 1934.

4) Bronk, D. W., Ferguson, L. K., Margaria, R. \& Solandt, D. Y. The activity of the cardiac sympathetic centers. Amer. J. Physiol. 117: 237, 1936.

5) DontaS, A. S. Effects of protoveratrine, serotonin and A. T. P. on afferent and splanchnic activity. Circulation Res. 3: 365, 1955.

6) Engelhorn, R. Aktionspotentiale der Nierennerven. Arch. Exp. Path. Pharmacol. 231: 219, 1957.

7) Euler, U. S. von, Liljestrand, G. \& ZotTerman, Y. The excitation mechanism of the chemoreceptors of the carotid body. Skand. Arch. Physiol. 83: 132, 1939.

8) Fischer, T., RAUle, W. \& Seraphin, R. Über die Spontantätigkeit sympathischer Herznerven in Abhängigkeit von Narkose, Blutdruckänderungen, Atmung und Adrenalin. Pflügers Arch. ges. Physiol. 262: 72, 1955.

9) Gernandt, B. \& Zotterman, Y. The splanchnic efferent outflow of impulses in the light of ergotamine action. Acta physiol. scandinav. 11: 301, 1946.

10) HERING, H. E. Der Blutdruckzüglertonus in seiner Bedeutung für den Parasympathikustonus und Sympathikustonus. Leipzig: Thieme. 1932.

11) IGGo, A. \& VoGT, M. Preganglionic sympathetic activity in normal and in reserpinetreated cats. J. Physiol. 150: 114, 1960.

12) KoCH, E. Die Irradiation der pressorezeptorischen Kreislaufreflexe. Klin. Wochenschr. 11: $225,1932$.

13) $\mathrm{KoCH}$, E. Irradiation der pressorezeptorischen Kreislaufreflexe auf das animale Nervensystem. Z. Kreisl. Forsch. 24: 251, 1932.

14) Moissejeff, E. Zur Kenntnis des Carotissinusreflexes. Z. ges. Exp. Med. 53: 696, 1926

15) Nisida, I., OKADA, H. \& NaKano, O. The activity of the cilio-spinal centers and their inhibition in pupillary light reflex. Jap. J. Physiol. 10: 73, 1960.

16) OKADA, H., NAKANo, O. \& NisIDA, I. Effects of sciatic stimulation upon the efferent impulses in the long ciliary nerve of the cat. Jap. J. Physiol. 10: 327, 1960. 